\title{
КОГНИТИВНЫЕ АСПЕКТЫ ПРЕДСТАВЛЕНИЙ И ПСИХОЭМОЦИОНАЛЬНОЕ СОСТОЯНИЕ СТУДЕНЧЕСКОЙ МОЛОДЕЖИ В ПЕРИОД ДИСТАНЦИОННОГО ОБУЧЕНИЯ В УСЛОВИЯХ ПАНДЕМИИ
}

\author{
Берберян А.С. (Российско-Армянский университет, Ереван, Армения) \\ aspsy@inbox.ru \\ 乙tipluјшgर्uाu uर्u. 27.07.2021 \\ 9pupunuर्ume uर्जu. 10.08.2021

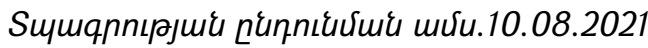

\begin{abstract}
В статье рассматриваются психолого-педагогические аспекты дистанционного обучения в системе высшего образования в условиях пандемии. Методологическая основа нашего исследования - концептуальные основы профессионального становления личности и деятельности (К.С. Абульханова-Славская, Б.Г. Ананьев, А.Г. Асмолов, С.Д.Смирнов), развития современных информационно-коммуникационных технологий (А. А. Андреев, Е. С. Полат, М. Ю. Бухаркина, М. В. Моисеева и др.); психоэмоциональных состояний личности (К.Изард, Г.Селье), а также положения гуманистической психологии (А. Маслоу, К. Роджерса и др.). Рассмотрены специфика дистанционного обучения, преимущества и недостатки обучения для субъектов образовательной деятельности в условиях пандемии. Важное значение приобретает исследование адаптированности и регуляции стресса студентов в целях поиска и выявления возможностей для эффеективного.

Цель исследования - изучение когнитивных аспектов представлений и психоэмоциональных состояний личности студентов в период дистанционного обучения в условиях пандемии. Основные методы исследования - анализ научной литературы, анкетирование, тестирование субъектов образовательной деятельности относительно различных аспектов онлайн-обучения в условиях пандемии, выявление их представлений. На основе результатов эмпирического исследования проводится интерпретация данных и делаются выводы.
\end{abstract}

Ключевые слова: представления, психоэмоциональное состояние, студенческая молодежь, дистанционное обучение.

DOI: https://doi.org/10.46991/SBMP/2021.4.2.096

Образование личности является важнейшей общечеловеческой проблемой в современном мире. Особенно в XXI веке это стало наиболее значимым 
условием, так как это век информатизации и компьютеризации всех сфер жизнедеятельности. Важность дистанционного образования в науке была представлена в своих работах следующими учеными: М.Ю. Бухаркиной, Ю.П. Господарика, М.П. Карпенко, Е.С. Полат, Е.Б. Сергиенко, В.П. Тихомировой, и др. Они отразили свои представления относительно сути и содержания дистанционного образования. К изучению дистанционного образования исследователи подходят с различных позиций: дистанционное обучение рассматривается как «получение услуг образования вдали от учебного заведения» [8]; представляет собой метод обучения, практику, «связывающую преподавателя, студента и источники, которые расположены на различной территории, с помощью особых новейших технологий, обеспечивающих взаимодействие» [9]; является «синтетической, интегральной гуманистической формой обучения, с применением как традиционных методов, так и новейших информационных технологий» [10].

Заметим, что данные формулировки не отражают многогранность дистанционного обучения: не учтен факт, что студенты могут находиться и на близлежащей территории, также не учитывается возможный контакт между студентами друг с другом. Демонстрацией успешной реализации дистанционной формы образования, по свидетельству исследователей, - e-learning, основанная на электронном обучении с помощью сети Интернет и мультимедий, практикуемых в Южной Корее, США, Франции, Японии других странах [8].

Итак, что же представляет собой дистанционное образование? Дистанционное образование - это многосторонняя гуманистическая модель преподавания, которая базируется на применении значительного диапазона информативных, классических также промышленных средств, какие, в собственную очередность, направляют требование беспрепятственного подбора просветительных дисциплин [15].

Мы считаем, что это такая форма обучения, при которой субъектами образовательной деятельности реализуется передача и усвоение информации через виртуальную среду, которая определяется при помощи стратегии преподавания и обучения, базируясь на специальной системе организации учебного процесса, приемов и методов разработки учебных дисциплин, использовании электронных и интернет-коммуникационных технологий. Информационные технологии и виртуальная среда еще не стали общекультурной практикой, но имеют большой потенциал для развития образования. В содержательном аспекте в традиционной системе дистанционного обучения компоненты: «знание - умение - навыки - осознание - понимание - внедрение» объединяются в дидактические элементы обучающих моделей образования, которые модифицируются в модель: «творческое осмысление проблемы -воспроизведение личностью на базе 
своего опыта - планирование - построение гипотезы - решение проблем новыми способами - их применение - введение в личностную систему» [2].

Достоинствами дистанционного образования являются:

- детально разработанные методики обучения, которые проверены временем и применяются для больших групп студентов,

- отсутствие ограничений относительно количества студентов по определенным курсам,

- наличие возможности у студентов выбрать удобный для себя график учебной деятельности, что обеспечивает индивидуализацию обучения,

- наличие возможности у студентов выбрать преподавателя, являющегося экспертом по определенной учебной дисциплине [6, 7]. Негативные особенности в дистанционном обучении - это отсутствие непосредственного контакта, определяющего необходимость направить свое внимание на психологические особенности организации обучения, которыми в значительной мере детерминируются эффрективность и качество образования [5, 14].

Цели дистанционного обучения на самом деле те же, что и при очном обучении, и имеют то же содержание. Но оно характеризуется иными формами изучения материала, формами контакта преподавателя и студентов, а также отличается взаимодействием студентов друг с другом. Анализируя отечественные и зарубежные источники, замечаем единодушность исследователей относительно дистанционного образования. Обратим внимание на особенности дистанционного образования, отличающие дистанционное от традиционного обучения: гибкость; модульность; параллельность; охват; экономность; технологичность; социальное равноправие; интернациональность, новая роль преподавателя [4, 6, 9, 13]. Студенческий возраст характеризуется достижением высших результатов, на всех предшествующих процессах психологического, биологического, социального развития. Этот возраст также характерен тем, что является самым благоприятным для развития интеллектуальных и фризических сил. В условиях распространения коронавирусной инфекции COVID-19 в системе высшего образования произошли всеобщие и молниеносные переходы от традиционного к дистанционному обучению. Такой резкий переход на "дистант" является вынужденной мерой в сложившейся ситуации, связанной с высоким риском заражения коронавирусом. Самоизоляция негативно воздействует на эмоциональное состояние человека, в особенности молодых людей, проявляясь в фрорме тревоги, стрессов, депрессии, посттравматического стрессового расстройства. Актуальность проблемы изучения эмоционального состояния студентов обусловлена необходимостью выявления его специфики и разработки программы психопрофилактики и психокоррекции студентов в условиях пандемии. Студенчество - период активного развития интеллектуальных, нравственных, социально-психологических и эстетических 
чувств, становления и формирования характера и, что особенно важно, реализация личности в гражданских, профессионально-трудовых, социальных и др.сорерах. Значимыми для юности являются осмысление и принятие ответственности при формировании жизненных планов перед самим собой, перед социумом. Жизненный план является планом потенциально возможных действий. В содержании планов, как указывал И.С. Кон, имеются когнитивные представления, мнения, иногда носящие противоречивый характер. [12]. В своих представлениях, связанных с будущей личной, профессиональной деятельностью и семейной жизнью, юноши и девушки достаточно реалистичны. А в сорере образования, карьеры и материального благополучия их притязания нередко завышены. Их представления и мнения сопровождаются эмоциональным настроем и эмоциональными состояниями. На протяжении всего процесса обучения у студентов фрормируются мировоззрение, знания, навыки и умения рациональной организации умственной деятельности, развивается мотивация к избранной профессии, вырабатывается оптимальный ритм жизнедеятельности, совершенствуется системная работа по самообразованию и самореализации значимых качеств личности. Значимы также субъективные психоэмоциональные представления студентов, отражающихся в форме непосредственных переживаний, ощущений широкий спектр отношения к миру и людям, к социальной ситуации в стране и глобальном мире: пандемии, кризисных состояниях, которые в конечном итоге формируют их поведенческие паттерны, выполняющие ряд функций: стимулирующую, регуляторную, оценочную, информационную $[11,16]$. В эмоциональных процессах, которые носят субъективный характер, своеобразно отражаются планы и ожидания студентов, проявляется отношение ко всему, что он осознает и что происходит вокруг. Именно психоэмоциональные состояния личности обогащают внутренний мир, привносят яркие и содержательные переживания, способствующие перестройке его взглядов, побуждают к активной деятельности и преодолению трудностей [17]. Представления студентов эмоционально насыщенны, для них характерны интенсивность, противоречивость, разнообразие, нестандартность, ускоренное формирование высших чувств [3,19]. В деятельности студента также присутствует эмоциональный стресс - напряженность в сложных ситуациях. Б.Г. Ананьев отмечает, что условия жизнедеятельности и труда личности рассчитаны не столько на думающего, сколько на чувствующего человека $[1,18]$. Таким образом, студенты способны эффрективно отражать в эмоциональной сорере свои убеждения и мнения, используя свое эмоциональное отношение для решения жизненно важных задач: социальных, профессиональных, учебных и др..

Гипотезы исследования: мы предполагаем, что: 
1. существует взаимосвязь между удовлетворенностью процессом обучения в дистанционном формате студентами и уровнем регуляции стресса;

2. существует корреляция между субъективной оценкой студентами качества образования с использованием дистанционного обучения и уровнем их адаптированности;

3. существует корреляция между адаптированностью и уровнем регуляции стресса у студентов.

Цель исследования: изучение дистанционного обучения $и$ его возможностей при определении когнитивных аспектов представлений и психоэмоционального состояния студенческой молодежи в условиях пандемии.

Методологическая основа нашего исследования - концептуальные положения профессионального становления личности и деятельности (К.С. Абульханова-Славская, Б. Г. Ананьев, А. Г. Асмолов, С.Д.Смирнов), развития современных информационно-коммуникационных технологий (А. А. Андреев, Е. С. Полат, М. Ю. Бухаркина, М. В. Моисеева и др.); психоэмоциональных состояний личности (К.Изард, Г.Селье), а также положения гуманистической психологии (А. Маслоу, К. Роджерс и др.).

Методы исследования: анкетирование и тестирование, в том числе методики: тест «Диагностика состояния стресса» (автор А. Прохоров); методика исследования адаптированности студентов в ВУЗ-е, автор Т. Дубовицкая, А. Крылова (шкалы адаптированности к учебной группе, адаптированности к учебной деятельности), авторская анкета, включающая вопросы относительно эффективности дистанционного обучения, способов и приемов усвоения учебного материала.

Выборка: в исследовании принимали участие 76 студентов различных вузов, из них 39 человек женского (1 группа) и 37 человек мужского пола (2 группа). Без сомнения, исследование не претендует на тотальную репрезентативность. Но результаты представляются симптоматичными для изучения представлений об эфрфективности онлайн-формата в обучении. Выявленные результаты убедительно демонстрируют положительное отношение преобладающего большинства респондентов к применению электронной системы обучения в учебной деятельности вуза.

Результаты исследования. Исходя из данных методики "Диагностика состояния стресса» (автор Прохоров), становится ясно, что у студентов 1 группы высокий уровень регуляции в стрессовых ситуациях. Они ведут себя в стрессовой ситуации довольно сдержанно и умеют регулировать свои собственные эмоции. А студенты 2 группы обладают умеренным уровнем регуляции в стрессовых ситуациях. Они не всегда правильно и адекватно ведут себя в стрессовой ситуации. 
Следующим исследованием являлась методика Т. Дубовицкой, А. Крыловой, направленная на исследование адаптированности студентов в вузе: результаты первой группы свидетельствуют о том, что студенты ощущают себя в группе комфортно, легко общаются с однокурсниками и ориентируются на групповые нормы и правила. А в плане освоения учебных дисциплин студенты успешны и проявляют стремление к саморазвитию. У студентов 2 группы уровень адаптированности к группе и к учебной деятельности ниже среднего уровня. Это свидетельствует об испытываемых студентами трудностях в общении с однокурсниками. Низкие результаты по шкале адаптированности к учебной деятельности свидетельствуют о том, что студентам сложно освоить учебные задания.

По результатам вопросов анкеты: наиболее выражен процент студентов с самооценкой адаптированности на хорошем и удовлетворительном уровнях. Как признают студенты, уровень мотивации в основной массе снизился. Результаты анкеты по вопросу удовлетворенностью процессом обучения в дистанционном формате студентами: более трети студентов отметили, что неудовлетворены. Проблемы, связанные с трудностями обучения в онлайнрежиме студенты оценивают следующим образом: сложности в коммуникации (30. 4\%), сложность выполнения практических занятий $(16,1 \%)$, сложности в усвоении материала (14, 3 \%), остальные проблемы незначительно выражены. Результаты анкеты по вопросу качества дистанционного обучения студентов: сомнения (32, 1 \%), отрицательно (32, 1 \%), положительно (32, 1\%). Соответственно эффрективность дистанционного обучения студентами оценивается как средняя $(39,3 \%)$, низкая $(33,9 \%)$. Оценка собственной работы в рамках дистанционного обучения в половине случаев - удовлетворительная $(41,1 \%)$, затем студенты разделились по группам: хорошо $(28,6 \%)$ и отлично $(28,6 \%)$.

По первой гипотезе мы выявили корреляцию между удовлетворенностью процессом обучения в дистанционном формате студентами и уровнем регуляции стресса - 0,43. В соответствии со второй гипотезой: между субъективной оценкой студентами качества образования с использованием дистанционного обучения и уровнем их адаптированности корреляционный коэффрициент составил 0,72. Таким образом, вторая гипотеза, которая заключалась в том, что существует связь между адаптацией личности и уровнем стрессоустойчивости студента 1 и 2 групп подтвердилась. В результате корреляционного анализа адаптированности и уровня регуляции стресса были получены следующие результаты: 0, 64.

Обсуждение результатов. На основе данных методик можно заметить, что уровень корреляционного коэфффициента адаптированности и уровня регуляции стресса составляет 0,64. Это говорит том, что наблюдается средняя 
прямая корреляция между адаптированностью и уровнем регуляции стресса, т. е. адаптированность влияет на уровень регуляции стресса. Мы выявили диффреренцированную картину обучения студентов в дистанционном фрормате. Это говорит том, что наблюдается сильная прямая корреляция между адаптацией и стрессоустойчивостью, т. е. адаптация является одним из факторов, воздействующих на стрессоустойчивость. Таким образом, третья гипотеза, которая заключалась в том, что существует взаимосвязь между уровнем адаптированности и уровнем регуляции стресса, подтвердилась. На наш взгляд, эфффективность дистанционного обучения в значительной степени зависит от студентов, так как они сами в половине случаев оценивают свою работу как удовлетворительную, то осознание дистанционного обучения как совместной работы привело бы к решению многих проблем, возникающих в онлайн-обучении.

Выводы: 1. Развитому обществу нужна личность, способная к самообразованию. Дистанционное обучение способно обеспечить непрерывный образовательный рост человека. Удаленное образование фактически является фрормой обучения, ориентированного на обучающихся. Она представляет собой свободу выбора педагога, возможность выбора учебного материала в соответствии с информационными потребностями студента. 2. По первой гипотезе мы выявили корреляцию между удовлетворенностью процессом обучения в дистанционном формате студентами и уровнем регуляции стресса. В соответствии со второй гипотезой в результате корреляционного анализа была выявлена высокая положительная связь между субъективной оценкой студентами качества образования с использованием дистанционного обучения и уровнем их адаптированности. Третья гипотеза о существовании взаимосвязи между уровнем адаптированности и уровнем регуляции стресса получила подтверждение. Система удаленного обучения может и должна занять свое место в системе образования, так как при правильной организации она может предложить высококачественное образование, отвечающее потребностям современного общества сегодня и в ближайшем будущем. Будущие исследования в этой области можно посвятить более детальному изучению возможности перехода к сетевым технологиям дистанционного обучения, основанным на использовании Интернета как нового средства познания и коммуникации.

\section{Литература}

1. Ананьев Б.Г. О проблемах современного человекознания. Изд-во Наука, М., 1977, 380 с.

2. Бедерханова В.П. Личность в образовательном процессе //Личность и бытие: теория и методология: Материалы Всероссийской научно- 
практическойконференции/Под ред. 3.И.Рябикиной, В.В.Знакова. Краснодар, 2003. С.41-53 ISBN 5-8209-0230-0

3. Берберян А.С. Экзистенциально-гуманистическая психология как фундаментальное основание концепции личностно-центрированного обучения в системе высшего образования Монография, Прага:Vedeckovydavatelskecentrum «Sociosfera -CZ., 2018., 299 с. РИНЦІSВN 978-80-7526-260-8.

4. Бухаркина М. Ю. Теория и практика дистанционного обучения / М. Ю. Бухаркина, М. В. Моисеева, Е. С. Полат. М. : Академия, 2004.

5. Вымятнин В.М., Демкин В.П., Нявро В.Ф. Дистанционное образование и его технологии. - Томск, 1998.

6. Господарик, Ю.П. Дистанционное обучение и средняя школа [Текст] / Ю.П. Господарик // Дистанционное образование. - №5. с.10-17.

7. Густырь А.В. Проблемы нормативного обеспечения и выбора базовой модели дистанционного образования // Дистанционное образование в России. Постановка проблемы и опыт организации. Сост. Овсянников В.И. - М.:РИЦ "Альфа" МГОПУ им. М.А. Шолохова, 2001.

8. Дистанционное обучение и новые технологии в образовании - М., 1995..

9. Дистанционное образование в России. Постановка проблемы и опыт организации. Сост. Овсянников В.И. - М.:РИЦ "Альфа" МГОПУ им. М.А. Шолохова, 2001.

10. Дистанционное обучение: Учебное пособие / Под ред. Е.С. Полат. - М.: Гуманит. изд. Центр ВЛАДОС, 1998. - 192 с.

11. Захарова Л.Н. Личностные особенности, стили поведения и типы, профессионально самоидентификации студентов педагогического вуза // Вопросы психологии, 1998. - № 2.

12. Кон И.С. Психология юношеского возраста / И. С. Кон - М., 2013. - 176 c.

13. Можаева Г.В. Учебный процесс в системе дистанционного образования // Открытое и дистанционное образование. - 2000. - № 1. - С.11 - 17.

14. Мур М. Г. Информационные и коммуникационные технологии в дистанционном образовании/М. Г. Мур, У. Макинтош, Л. Блэк и др. М.: Обучение-Сервис, 2006).

15. Овсянников В.И. Структура дистанционного образования.//Дистанционное образование в России. Постановка проблемы и опыт организации. Сост Овсянников В.И. - М.:РИЦ "Альфа" МГОПУ им. М.А. Шолохова, 2001. - С.51.

16. Рейковский Я. Эмоции как процесс, организующий поведение. - М., 2008 
17. Соколов Г.А. Особенности психоэмоциональных состояний студента при дистанционной форме обучения. // Педагогика и просвещение. 2014. № 1 . Стр. 1-13.

18. Фёдорова Е.Е. Адаптация студентов ВУЗов к учебно-профессиональной деятельности. - Магнитогорск, 2007 - 13.00.08

19. Berberyan A.S., Berberyan H.S. Ethnopsychological aspects of the meaning-of-life and value orientations of Armenian and Russian students. Psychology in Russia: State of the Art, 9(1), Scopus, 2016 стр. 121-137. DOI: 10.11621/pir.2016.0109 Pages: 121-137. Themes: Multiculturalism and intercultural relations: Comparative analysis

20. Arie W. K., Szumowska E. Habitual Behavior Is Goal-Driven June 22, 2020 Research Articlehttps://doi.org/10.1177/1745691620917676.

\section{COGNITIVE ASPECTS OF REPRESENTATIONS AND PSYCHOEMOTIONAL STATE OF STUDENT YOUTH DURING DISTANCE LEARNING IN A PANDEMIC}

Berberyan A.S. (Russian-Armenian University, Yerevan, Armenia)

The article examines the psychological and pedagogical aspects of distance learning in the higher education system in a pandemic. The methodological basis of our research is the conceptual foundations of the professional formation of a person and activity (B. G. Ananiev, A. G. Asmolov, S. D. Smirnov), the development of modern technologies (A. A. Andreev, E. S. Polat, M. Yu. Bukharkina and others); psychoemotional states of personality (K. Izard, G. Selye), the provisions of humanistic psychology (A. Maslow, K. Rogers, etc.). It is important to study the adaptation and regulation of students' stress. The aim of the research is to study the cognitive aspects of the ideas and psychoemotional states of the personality of students during the period of distance learning in the context of a pandemic. The main research methods are analysis of scientific literature, questionnaires, testing of subjects of educational activity regarding various aspects of online learning in a pandemic and identifying their views. Based on the results of empirical research, the data are interpreted and conclusions are drawn.

Keywords: representations, psychoemotional state, student youth, distance learning. 